\title{
Strategic Choice of Manufacturing Planning and Control Approaches: Empirical Analysis of Drivers and Performance
}

\author{
Jan Olhager and Erik Selldin \\ Linköping University, Department of Management and Engineering, \\ SE-58183 Linköping, Sweden \\ jan.olhager@liu.se,www.liu.se
}

\begin{abstract}
The design of manufacturing planning and control systems is a strategic decision for manufacturing firms. In this paper we analyze the interrelationships among the choices of planning and control approaches at different hierarchical levels, including sales and operations planning (chase; level), master scheduling (make-to-order; assemble-to-order; make-to-stock), material planning (time-phased; rate-based), and production activity control (MRP-type; JIT-type). We test the relationships with product characteristics and performance. These relationships are explored through a survey of 128 manufacturing plants.

The results show that choice of approaches at the two higher planning and control levels, i.e. sales and operations planning and master scheduling, are strongly interrelated. The choices at the two lower hierarchical levels, i.e. material planning and production activity control, are also strongly interrelated. However, the link between any of the two upper and any of the two lower levels is much weaker. The most significant drivers of the choice of planning and control approach are: (i) product volume and delivery lead time for sales and operations planning, (ii) product variants and delivery lead time for master scheduling, and (iii) production lead time for production activity control, while material planning is not significantly related with any product characteristic. Significant effects on performance are found for sales and operations planning on volume flexibility, master scheduling on product mix flexibility, and material planning and production activity control approaches on delivery speed. This research supports the notion that sales and operations planning is concerned with volume planning and that master scheduling is concerned with mix planning.
\end{abstract}

Keywords

Empirical analysis, Manufacturing, Performance, Survey research, Theory testing

Please use the following format when citing this chapter:

Olhager, J., Selldin, E., 2007, in IFIP International Federation for Information Processing, Volume 246, Advances in Production Management Systems, eds. Olhager, J., Persson, F., (Boston: Springer), pp. 35-42. 


\section{Introduction}

In order to achieve manufacturing excellence the planning and control system for manufacturing operations must fit the task relative the market place. The design of a manufacturing planning and control (MPC) system cannot be taken in isolation; it must be based on the specific products produced and their market characteristics. The design of an MPC system is a strategic choice related to the operations strategy. A framework for choosing the appropriate type of planning and control approach relative the market and product characteristics, has been developed by Berry and Hill [1], also presented in $[2,3]$. They are concerned with three hierarchical planning levels, i.e. master planning, material planning, and shop floor control. The fourth level in an MPC system is sales and operations planning, which has been added to the Berry and Hill framework by Olhager et al. [4], concerned with the choice of planning strategy. The theoretical models are assumingly sound, have been widely referenced, and have not received specific criticism in the literature. Therefore, it is interesting to test these theories on how to design MPC systems related to the market and product characteristics, drawing on the modeling ideas in Berry and Hill [1], with the amendment of Olhager et al. [4]. This paper extends the analysis in Olhager and Selldin [5] by addressing drivers and individual performance measures.

This paper is organized as follows. First, we present the theoretical framework underpinning this research. Then, we discuss the research methodology in terms of the data and measurements used. We then present the survey results, including the interrelationships among the planning and control approaches at different hierarchical levels, the relationships between product characteristics and the choice of planning and control approaches, and the relationships between planning and control system choices and performance outcomes.

\section{Theoretical Framework}

The models for linking market characteristics to the design of an MPC system can basically be reduced to one, first presented in Berry and Hill [1], and later included in $[2,3]$. In the Berry and Hill framework there are links and choices at three levels of the MPC system. At each level a set of market requirement attributes are used to make generic choices among a set of level-dependent MPC design variables. At the master scheduling level the choices are reduced to three variables; make-to-order (MTO), assemble-to-order (ATO), or make-to-stock (MTS). ATO covers for similar environments such as build-to-order (BTO), configure-to-order (CTO), and finish-toorder (FTO). At the materials planning level the choices are rate-based or timephased. Finally, at the shop floor control level the choices are push or pull. The attributes linking market and product characteristics to the MPC approaches are very much the same, namely product type, product range and individual product volume per period, cf. Table 1. Examples of this framework conformity is that firms with high-volume standardized products typically would choose MTS, rate-based, and pull, whereas firms with many low-volume, customized products would choose MTO, time-phased, and push. In ATO environments both sets of MPC choices are 
applicable to different sections of the value chain upstream versus downstream the customer order decoupling point (CODP). In the case of ATO or similar environments, volumes are typically sufficiently high upstream the CODP to make MTS/rate-based/JIT-type approaches possible, whereas MTO/time-phased/MRPtype approaches are typically required after the CODP due to customized features and low volumes per product. Thus, ATO environments can typically be divided into MTS-type operations upstream and MTO-type operations downstream the CODP.

The three levels used in the Berry and Hill framework are the lower three of four levels, typically found in an MRPII (manufacturing resource planning) hierarchy. The upper level is sales and operations planning (S\&OP), which has been added to the Berry and Hill framework by Olhager et al. [4]. A chase strategy would assumingly be used for low-volume, highly customized products, whereas a level strategy would be more suitable for high-volume, standardized products. This addition to the Berry and Hill framework is included in Table 1. Alignment between product characteristics and MPC approaches is assumed when there is a straight vertical line in Table 1.

Table 1. Linking planning and control system to the market and product characteristics, according to Berry and Hill [1] and Olhager et al. [4].

\begin{tabular}{lccc}
\hline Market and product characteristics: & & & \\
Product type $^{2}$ & Special & $\rightarrow$ & Standard \\
Product range $^{2}$ & Wide & $\rightarrow$ & Narrow \\
Individual product volume per period $^{2}$ & Low & $\rightarrow$ & High \\
\hline Planning and control level: & & & \\
Sales and operations planning (S\&OP) $^{1}$ & Chase & & Level \\
Master scheduling (MS) $^{2}$ & MTO & ATO & MTS \\
Material planning (MP) $^{2}$ & Time-phased & & Rate-based \\
Production activity control (PAC) $^{2}$ & MRP-type & & JIT-type \\
\hline
\end{tabular}

${ }^{1}$ Source: $[4] ;{ }^{2}$ Source: [1].

While the framework in Table 1 mostly deals with manufacturing operations, Fisher [6] developed a framework for supply chains, linking product characteristics with supply chain design types. Products that are innovative are characterized by demand variability and short product life cycles, they should therefore be transformed through a market-responsive supply chain that has extra capacity, capability of market information processing and that is more flexible. On the other hand, a steady demand pattern, high volumes and long product life cycles characterize products that are functional. A physically efficient supply chain that focuses on cost minimization and high utilization of resources should handle this kind of products. Thus, there is some resemblance with the framework in Table 1. Functional products are basically characterized as standard, narrow range, and high volume, whereas innovative products are special, wide range, and low volume. A physically efficient supply chain would assumingly be able to utilize a level strategy, MTS, rate-based, and JITtype approaches, whereas a market-responsive supply chain would prefer a chase strategy, MTO, time-phased, and MRP-type approaches. The conceptual model is illustrated in Figure 1. 


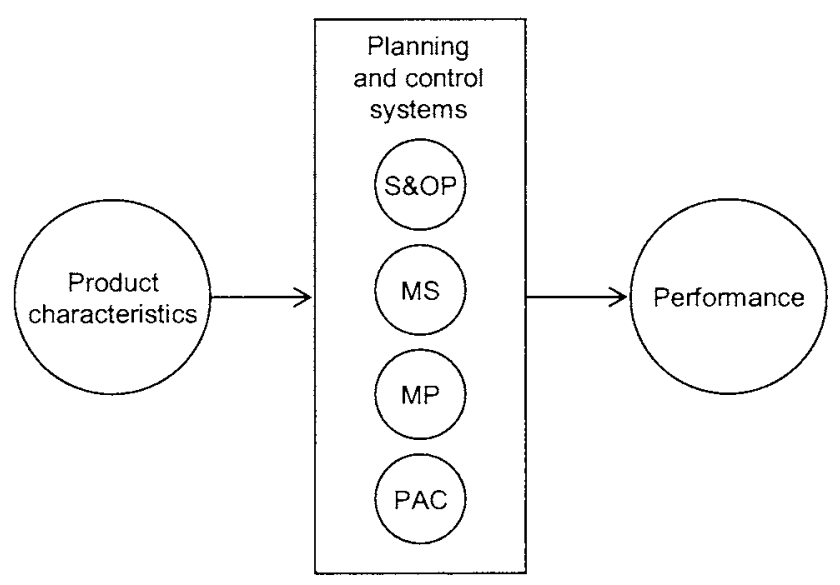

Fig. 1. Illustration of the relationship between product characteristics, planning and control system, and performance.

\section{Data and Measurements}

The variables for measuring planning and control are related to the different planning levels such as described in [1-4]. Sales and operations planning is measured using a five step Likert scale ranging from a pure chase planning strategy to a pure level strategy. Master scheduling ranging from pure make-to-order to pure make-to-stock, materials planning ranging from pure time-phased to pure rate-based, and production activity control ranging from pure MRP-type to pure JIT-type are all measured using floating scales where the respondents indicate the percentage of planning using each approach.

The product characteristics are based on the Berry and Hill model, with additions by Fisher [6]. All variables are captured using five step Likert scales. Demand volume and number of variants are central product characteristics in Berry and Hill [1], but also in the product-process matrix by Hayes and Wheelwright [7]; a wellknown operations strategy model for linking products and processes. In the survey, product volume is captured by a variable ranging from one-of-a-kind product to mass-produced products. The number of variants is captured by a variable ranging from few variants to many variants. Other relevant product characteristics are the effect of seasonal demand (low to high seasonality) and delivery lead time for maketo-order products; cf. Fisher [6]. However, we divide the latter into two variables, delivery lead time and production lead time, to allow not only for make-to-order situations but also for make-to-stock or assemble-to-order situations where there is a difference between production and delivery lead times. Both delivery and production lead times measures range from short to long lead times. 
Performance is measured as the respondent's perceptions of the company's performance related to competitors. All variables are measured using five step perceptual Likert scales ranging from "much worse than competitor" to "much better than competitor". The performance is measured by operational performance in terms of quality, delivery dependability, delivery speed, cost efficiency, volume flexibility, and product mix flexibility.

\section{Survey}

The questionnaire was mailed to 511 manufacturing firms, and 128 usable responses were received. This represents a response rate of 25.0 percent. All respondents are members of PLAN, the Swedish Production and Inventory Management Society, wherefore they all assumingly possess good knowledge about MPC approaches. Single-item measures are used in order to describe the components of the theoretical framework. The unit of analysis in this study is the main product line at the plant level, and the corresponding MPC system. The responding plants represent the whole spectrum of the five generic process choices: project manufacturing, job shop, flow shop, production line, and continuous processing. Both make-to-order and make-tostock production environments are represented, as well as both consumer goods manufacturers and industrial goods manufacturers. The distribution of different kinds of environments indicates that the sample is representative for the manufacturing industry.

\section{Results and Analysis}

In this section we investigate the relationships between different planning and control approaches at different hierarchical levels, i.e. at the S\&OP, MP, MS and PAC levels. First, we check the consistency among the approaches chosen at different hierarchical levels. According to theory (see section 2), there should be positive relationships among on the one hand a chase, make-to-order, time-phased, and MRP-type approaches, and on the other a level, make-to-stock, rate-based, and JIT-type approaches. Secondly we test the relationships with product characteristics to identify possible differences among which characteristics that drive the choice of MPC approaches at different planning levels. Finally, we analyze the relationship with performance. The significant relationships are summarized in Figure 2. 


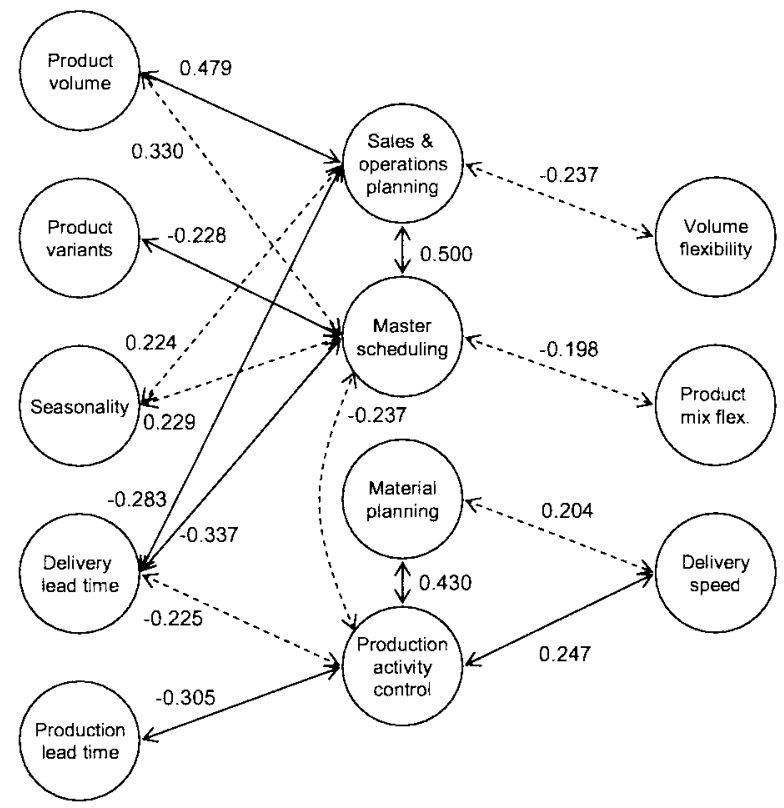

Fig. 2. The total model indicating all significant relationships between product characteristics, MPC approaches, and performance outcomes (a full line indicates significance at the 0.01 level, and a dotted line indicates significance at the 0.05 level).

\subsection{Consistency among MPC Approaches}

The results show that the relationship between the two higher planning and control levels is highly significant. Firms using a level planning strategy for sales and operations planning predominantly use a make-to-stock approach, whereas a chase strategy tends to be used by make-to-order firms. The relationship between the two lower hierarchical levels is also highly significant. Rate-based material planning is linked to JIT-type production activity control, and time-phased approaches tend to be combined with MRP-type approaches. However, the link between upper and lower levels is weak. There is actually a negative relationship (significant at the 0.05 level) between master scheduling and production activity control approaches, which was not expected. This means that make-to-stock firms tend to use MRP-type approaches to a larger extent that JIT-type approaches. Also, make-to-order firms use JIT-type approaches to a larger extent than MRP-type approaches.

\subsection{Relationship between Product Characteristics and MPC Approaches}

The theory-based model suggests that the product volume, number of variants and other market and product characteristics drive the choice of MPC approaches at all 
hierarchical levels. However, the result concerning consistency among MPC approaches suggests that there may be different drivers of the choice at different hierarchical levels.

Product volume is significantly related with the sales and operations planning approach (0.01 level) and with master scheduling approach ( 0.05 level), but not with the two lower MPC levels. With higher production volumes, firms tend to use a level strategy and apply make-to-stock, which is expected. The number of product variants is significantly correlated ( 0.01 level) with master scheduling approach. A firm with many variants typically operates on a make-to-order basis, which is expected. Seasonal effects is significantly correlated $(0.05$ level) with the sales and operations planning approach as well as with the master scheduling approach. Products with high seasonal variations often have a level planning approach and are produced to stock. Assuming that the goods can be stored, the firm can take advantage of a level strategy for make-to-stock operations. Delivery lead time is significantly related with the S\&OP approach (0.01 level), with the master scheduling approach (0.01 level), and with the production activity control approach $(0.05$ level). Short delivery lead times are related to a level planning strategy, make-to-stock, and JIT-type execution, whereas long lead times are associated with a chase planning strategy, make-toorder, and MRP-type execution. Production lead time is significantly correlated $(0.01$ level) with the production activity control approach. Products with long production lead-times are found to be associated with a push-type approach, while short production lead-times are associated with a pull-type approach.

In summary, the results strongly suggest that the end product characteristics that are related to the marketplace only dictates the choice of MPC approaches for S\&OP and master scheduling, i.e. the two planning levels that explicitly deal with end products and product groups (of end products), while the two lower levels are concerned with the detailed planning and execution of individual items at lower levels in the product structure (bill of material). Only delivery lead time showed a significant relationship to both upper and lower MPC levels. Product volume, the number of variants, and seasonality were only associated with upper MPC levels, while production lead time was only associated with one of the two lower MPC levels. The material planning approach did not show any significantly relationship with any of the product characteristics.

\subsection{Relationship between MPC Approaches and Performance Outcomes}

The performance variables are measured using a five-step Likert scale ranging from "much worse than competitors" to "much better than competitors". Only four significant correlations were found. The S\&OP approach is negatively correlated with volume flexibility such that high volume flexibility is linked with a chase planning strategy at the sales and operations planning level. At the next lower level, the master scheduling approach is negatively correlated with product mix flexibility, indicating that make-to-order is linked with high product mix flexibility. The two lower levels, material planning and production activity control are positively correlated with delivery speed, such that high delivery speed is linked with both ratebased and pull-type approaches. Thus, three different performance variables are 
associated with four different levels of the planning and control hierarchy. The linkages reflected by all four significant correlations are in line with theoretical expectations.

\section{Discussion}

In this paper we have investigated the relationships among planning and control approaches at different hierarchical levels (sales and operations planning, master scheduling, material planning, production activity control), product characteristics as potentials drivers of the choice of approach, and the relationships with operational performance through a survey with data from 128 manufacturing firms. The contribution to the existing literature from this study is the theory testing of models in the literature about how the choices of planning and control approaches are interrelated and how they are linked to market and product characteristics, and the possible effect on performance. The study supports the conceptual model [1-4]; especially for the sales and operations planning and master scheduling levels, which can be characterized as volume and mix planning, respectively, with respect to the significant relationships with product characteristics as well as performance outcomes.

The implications for managers is that the results show that the choice of MPC approaches at the two upper levels are driven by end product characteristics such as volume, variants, and seasonality, while the two lower levels are driven by the lead time for production and delivery. This suggests that the two lower levels are more related to specific item characteristics rather than end product characteristics.

\section{References}

1. W.L. Berry, and T. Hill, Linking systems to strategy, International Journal of Operations and Production Management, 12(10), 3-15 (1992).

2. T. Hill, Manufacturing Strategy - Text and Cases, $2^{\text {nd }}$ ed. (Palgrave, Houndsmills, Hampshire, 2000).

3. T.E. Vollmann, W.L. Berry, D.C. Whybark, and F.R. Jacobs, Manufacturing Planning and Control for Supply Chain Management, $5^{\text {th }}$ ed. (McGraw-Hill, New York, 2005).

4. J. Olhager, M. Rudberg, and J. Wikner, Long-term capacity management: linking the perspectives from manufacturing strategy and sales and operations planning, International Journal of Production Economics, 69(2), 215-225 (2001).

5. J. Olhager, and E. Selldin, Manufacturing planning and control approaches: environmental alignment and performance, International Journal of Production Research, 45(6), 14691484 (2007).

6. M. Fisher, What is the right supply chain for your product?, Harvard Business Review, 75(2), 105-116 (1997).

7. R.H. Hayes, and S.C. Wheelwright, Link manufacturing processes and product life cycles, Harvard Business Review, 57(1), 133-140 (1979). 